韩其飞,李莹荣,彭开兵,李超凡, 黄晓东, 许文强.大气氮沉降对中亚草地生态系统净初级生产力的影响.生态学报, 2021,41(21):8545-8555. Han Q F, Li Y Y, Peng K B, Li C F, Huang X D, Xu W Q.Effects of atmospheric nitrogen deposition on net primary productivity of grassland ecosystem in Central Asia.Acta Ecologica Sinica, 2021,41(21):8545-8555.

\title{
大气氮沉降对中亚草地生态系统净初级生产力的影响
}

\author{
韩其飞 ${ }^{1,2, *}$, 李莹莹 ${ }^{1}$, 彭开兵 ${ }^{1}$, 李超凡 ${ }^{1}$, , 晓东 $^{3}$, 许文强 4 \\ 1 南京信息工程大学地理科学学院,南京 210044 \\ 2 南京信息工程大学气象灾害预报预警与评估协同创新中心,南京 210044 \\ 3 兰州大学草地农业科技学院, 兰州 730020 \\ 4 中国科学院新疆生态与地理研究所,荒漠与绿洲生态国家重点实验室,乌鲁木齐 830011
}

摘要:氮沉降作为除气候变化、 $\mathrm{CO}_{2}$ 浓度升高以及土地利用变化之外的第四大主要影响陆地生态系统结构和功能的因素,其对 碳循环过程的影响研究相对薄弱, 同时也是不确定性最大的环节之一。近年来, 由于长期高强度的放牧导致草地生态系统的生 产力降低,氮成为典型草地植物生长和生态系统净初级生产力的主要限制因子。据研究,亚洲的氮沉降平均增速极有可能高于 全球氮沉降平均增速, 成为未来氮沉降增加最快的区域。在此背景下, 研究大气氮沉降对于中亚草地生态系统的影响具有重要 的意义。利用反硝化-分解模型 (DNDC) 分析 1979-2014 年中亚地区草地生态系统净初级生产力 (NPP) 的时空分异, 探讨氮沉 降对草地 NPP 影响。结果表明: ( 1 ) 1979-2014 年间, 中亚地区平均草地 NPP 约为( $173.10 \pm 31.80) \mathrm{g} \mathrm{C} \mathrm{m}^{-2} \mathrm{a}^{-1}$, 草地 NPP 时空 分异明显,各草地类型的 NPP 从大到小依次为森林草甸、温带草原和荒漠草原, 并且草地 NPP 以 $(2.67 \pm 1.30) \mathrm{g} \mathrm{C} \mathrm{m}^{-2} \mathrm{a}^{-1}$ 的速度 逐年增长; (2) 当前氮沉降情景总体上促进了中亚地区草地 NPP 的增长, 1979-2014 年氮沉降使得中亚草地 NPP 增加了 $0.42 \mathrm{Pg} \mathrm{C}_{\circ}$

关键词: 中亚地区; 氮沉降;净初级生产力 (NPP); 利用反硝化分解模型 (DNDC)

\section{Effects of atmospheric nitrogen deposition on net primary productivity of grassland ecosystem in Central Asia}

\footnotetext{
HAN Qifei ${ }^{1,2, *}$, LI Yingying ${ }^{1}$,PENG Kaibing ${ }^{1}$,LI Chaofan ${ }^{1}$, HUANG Xiaodong ${ }^{3}$, XU Wenqiang ${ }^{4}$

1 School of Geographical Sciences, Nanjing University of Information Science \& Technology, Nanjing 210044, China

2 Collaborative Innovation Center on Forecast and Evaluation of Meteorological Disasters, Nanjing University of Information Science \& Technology, Nanjing 210044, China

3 College of Pastoral Agriculture Science and Technology, Lanzhou University, Lanzhou 730020, China

4 State Key Laboratory of Desert and Oasis Ecology, Xinjïang Institute of Ecology and Geography, Chinese Academy of Sciences, Urumqi 830011, China
}

\begin{abstract}
Climate change, increased $\mathrm{CO}_{2}$ concentration, nitrogen deposition and land use change are currently recognized as the main factors affecting the structure and function of ecosystems. Among them, the research on the influence of nitrogen deposition on carbon cycling process is still insufficient with great uncertainty. In recent years, as the productivity of grassland ecosystem is reduced due to long-term intensive grazing, nitrogen has become a limiting factor of typical grassland. The increasing rate of nitrogen deposition in Asia is probably higher than the global average as reported by previous research. In view of this, it is of significant importance to study the effect of atmospheric nitrogen deposition on grassland ecosystem in Central Asia. In this study, Denitrification-Decomposition ( DNDC) model was utilized to analyze the temporal

基金项目: 江苏省基础研究计划自然科学基金面上项目 (BK20201393); 国家自然科学基金项目 (41971293); 荒漠与绿洲生态国家重点实验室开 放基金 ( G2019-02-03)

收稿日期: 2020-09-07; 网络出版日期: 2021-07-05

*通讯作者 Corresponding author.E-mail: hanqifei@ nuist.edu.cn
\end{abstract}


and spatial variation of grassland net primary productivity (NPP) in Central Asia from 1979 to 2014 , to explore the effects of nitrogen deposition on grassland NPP. The results showed that: ( 1) During 1979-2014, the annual averaged temperature in Central Asia showed a significant increase trend $\left((0.03 \pm 0.01){ }^{\circ} \mathrm{C} \mathrm{a}^{-1}, R^{2}=0.40\right)$, while the precipitation decreased with the trend of $(2.26 \pm 1.78) \mathrm{mm} \mathrm{a}^{-1}\left(R^{2}=0.35\right)$. (2) from 1979 to 2014 , the average NPP of grassland in Central Asia was about $(173.10 \pm 31.80) \mathrm{g} \mathrm{C} \mathrm{m}^{-2} \mathrm{a}^{-1}$, and the spatial and temporal differences of grassland NPP were obvious. The highest NPP of grassland was found in forest meadow, followed by temperate grassland, and desert grassland NPP. Moreover, the grassland NPP increased at the rate of $(2.67 \pm 1.30) \mathrm{g} \mathrm{C} \mathrm{m}^{-2} \mathrm{a}^{-1}$. (3) The current nitrogen deposition scenario generally benefits the growth of grassland NPP in central Asia, which increases the grassland NPP by 0.42 Pg C in the last 36 years. Based on the existing studies, we cannot determine whether the decrease of NPP in this part of grassland is caused by reaching the critical load of nitrogen, and more in-depth studies are needed.

Key Words: Central Asia; nitrogen deposition; grassland NPP; DNDC model

干旱半干旱区约占全球陆地总面积的 $41 \%^{[1]}$ 。受气候影响, 干旱区水资源匮乏,生态环境十分脆弱, 人 类活动和全球变化对该区陆地生态系统结构和功能的影响极大。因此,全球变化背景下,干旱区生态系统碳氮-水循环在全球碳循环研究中也具有重要的科学意义 ${ }^{[2]}$ 。中亚地区是全球典型的干旱区之一, 降水稀少, 极 其干燥, 草地作为其主要的植被类型, 具有极其重要的经济和生态价值 ${ }^{[3]}$ 。近 30 年来, 由于气候变化、长期过 度放牧以及风蚀等的影响, 该区部分地区出现土地沙漠化、盐渍化、草地退化等一系列问题 ${ }^{[4]}$, 探讨中亚草地 生态系统净初级生产力 (NPP) 对气候变化和人类活动的响应, 对于该地区草地生态系统的可持续发展至关 重要。

除气候变化、 $\mathrm{CO}_{2}$ 浓度升高以及土地利用变化之外,氮沉降是影响陆地生态系统结构和功能的第四大因 素 $^{[5-6]}$, 但其研究最为薄弱且不确定性最大 ${ }^{[7]}$ 。尽管大部分研究都发现, 氮沉降对草地生态系统生产力具有 促进作用 ${ }^{[8]}$, 但是长期的氮沉降使得生态系统中的氮含量增高, 当氮含量达到一定浓度后, 草地生态系统的 生产力将会降低, 即氮沉降对草地生产力的影响存在氮临界负荷 ${ }^{[9]}$ 。探究氮沉降对草地生产力的影响机理, 揭示典型草地生态系统的氮沉降临界负荷, 有助于加深草地生态系统碳循环对全球变化反馈的认识, 对维持 区域生态可持续发展具有重要意义。

传统的研究氮添加对生态系统影响的方法是施氮量级试验, 这种方法要对施氮量、施氮时间和施肥频率 的不同梯度进行完全的一一对应处理设计, 需要设计大量的试验小区。而且, 试验方法研究得到的结论受制 于试验年份和地点的限制。鉴于站点尺度直接观测法的局限性, 陆地生态系统模型成为基础研究普遍使用的 方法 ${ }^{[10]}$ 。模型通过设置大量情景模式, 模拟氮肥运筹对草地生产力和养分吸收的影响, 也可以在不同的时间 尺度和空间尺度上进行生态系统的动态变化研究。相对于传统的施氮量级试验, 模型模拟能够灵活控制气候 变化和作物管理模式,达到以最少的时间和物质投人,完成对最优氮素管理措施的探求。

综上所述,本研究拟基于反硝化-分解模型 (DNDC) 模型, 模拟 1979-2014 年中亚地区草地 NPP 时空分 异, 分析草地 NPP 对氮沉降的响应。在全球变化和人类活动对生态环境影响日益增强的背景下, 研究氮沉降 对中亚地区草地生态系统 NPP 的影响机制, 对充分发挥该地区草地生态系统的经济和生态价值, 提高对全球 变化的应对能力具有重要的科学意义。

\section{1 材料与方法}

\section{1 研究区概况}

研究区包括中国新疆和中亚五国 (哈萨克斯坦、乌兹别克斯坦、吉尔吉斯斯坦、土库曼斯坦和塔吉克斯 坦) 在内的中亚地区 $\left(34.3-55.4^{\circ} \mathrm{N}, 46.5-96.4^{\circ} \mathrm{E}\right)$, 研究区总面积约 $5.66 \times 10^{6} \mathrm{~km}^{2}$ 。中亚地区深居亚欧大陆 腹地, 距离海洋较远, 导致中亚大部分地区降水稀少且时空分布不均 ${ }^{[11]}$ 。冬冷夏热, 气温年较差和日较差较 
大, 昼夜温差常常在 $20-30^{\circ} \mathrm{C}$, 属典型的温带沙漠、草原的大陆性气候 ${ }^{[12]}$ 。受地形和气候等影响, 中亚地区主 要植被类型为草地、荒漠和耕地, 其中, 草地作为主要的植被类型广泛分布在中亚各个地区, 草地又可以分为 森林草甸 $(F M)$ 、温带草原 $(T G)$ 和荒漠草原 $(D G)^{[13]}$ 。温带草原主要分布在哈萨克斯坦北部,该区主要的植 被类型为丛生禾草, 由于该区阳光和热量充足,草原生长良好, 是主要的放牧区域; 荒漠草原广泛分布在中国 新疆、乌兹别克斯坦和哈萨克斯坦南部, 吉尔吉斯斯坦和塔吉克斯坦也有少量分布, 该区气候干燥, 年降雨量 $200 \mathrm{~mm}$ 以下, 蒸发量高达 $2300 \mathrm{~mm}$ 。夏季炎热, 冬季寒冷。土壤为砂质原始灰棕色荒漠土和残余荒漠盐土, 优势植物有琵琶柴、碱柴、怪柳、猪毛菜等; 森林草甸主要分布在吉尔吉斯斯坦、塔吉克斯坦和中国新疆海拔 $1650-2650 \mathrm{~m}$ 的中山区, 因处逆温带, 气候湿润温和, 冬暖夏凉。在向阳的沟谷中, 牧草生长茂盛, 植被种类 丰富, 以中生、中旱生植物为主( 图 1)。

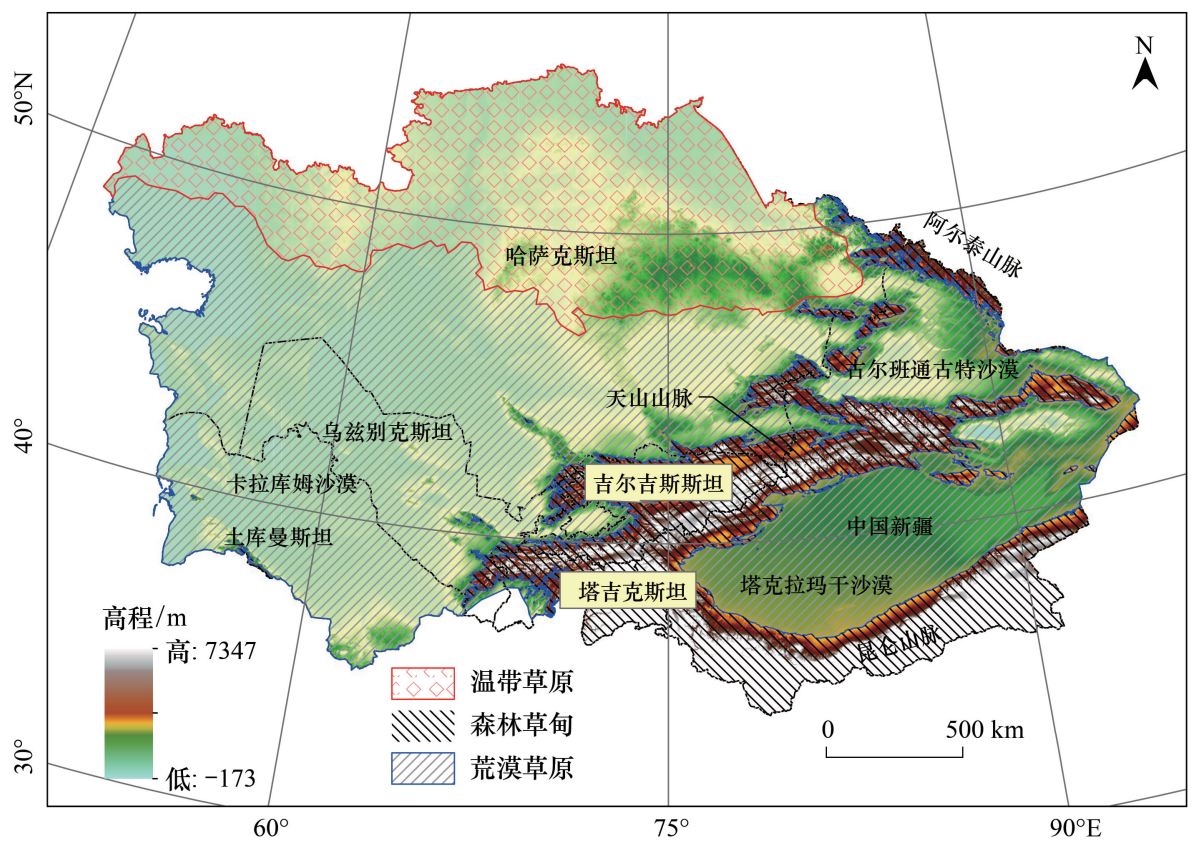

图 1 研究区地理位置及草地类型分布图

Fig.1 Distribution map of different grassland types in the study area TG: 温带草原 Temperate grassland;FM:森林草甸 Forest meadow; DG: 荒漠草原 Desert grassland

\section{2 数据来源}

本研究分别采用三套 1979-2014 年的气象再分析数据进行模拟, 以降低由于气象数据带来的不确定性。 MERRA(The Modern Era Retrospective-analysis for Research and Applications) 资料,来源于美国国家航空航天局 (NASA) 的 GESDISC (Goddard Earth Science Data Information and Services Center), MERRA 是利用 GEOS-5(The Goddard Earth Observing System Model V.5) 同化系统生成的再分析数据产品,水平分辨率为 $0.6667^{\circ} \times 0.5^{\circ[14]}$ 。 ERA-Interim 再分析资料是由 (European Centre for Medium-range Weather Forecasts, ECMWF) 发布的最新的再 分析数据产品, 水平分辨率为 $0.75^{\circ} \times 0.75^{\circ[15]}, \mathrm{CFSR}$ 气象再分析数据是美国国家环境预报中心的数据产品, 空间分辨率为 $0.3125 \times 0.3125^{\circ[16]}$ 。CFSR、ERA-Interim 和 MERRA 三套再分析数据在中亚大部分区域具有较 好的降水精度, 可作为生态模型在中亚地区模拟的气象驱动因子。

氮沉降数据来自 MIX 排放清单 ${ }^{[17]}$, 该数据包含亚洲 30 个国家和地区 2008 年和 2010 年的温室气体排放 数据, 以及人为源污染物数据, 包括 $\mathrm{NO}_{\mathrm{x}} 、 \mathrm{NH}_{3} 、 \mathrm{CO} 、 \mathrm{CO}_{2}$ 等十种主要大气化学成分, 以及五个排放部门(交通、 农业、电力、工业、民用) 的逐月网格化排放数据, 数据的空间分辨率为 $0.25^{\circ}$ 。本研究将所有空间数据统一到 了相同的投影并利用最邻近插值法重采样到相同的水平分辨率 $(40 \mathrm{~km} \times 40 \mathrm{~km})$ 。 


\subsection{DNDC 模型及情景模拟}

DNDC ( Denitrification-Decomposition) 模型, 是一个描述农业生态系统中碳和氮生物地球化学过程的计算 机模拟模型 ${ }^{[18]}$ 。经过长期的改进, 已广泛应用于几乎所有的陆地生态系统 ${ }^{[19]}$, 并且能够对作物产量做出较

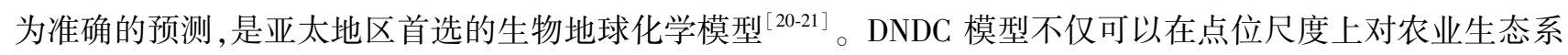
统中碳和氮的生物地球化学过程进行模拟, 而且在区域尺度也同样适用。在本研究中, 主要利用 DNDC 模型 的区域尺度模拟模式,通过控制气象和耕种管理等数据, 模拟得到不同情景下草地的 NPP。首先, 利用 CFSR、ERA-Interim 和 MERRA 三套气象数据驱动 DNDC 模型, 模拟当前大气氮沉降情景下中亚地区草地生态 系统的 NPP, 综合三套气象数据得到的模拟结果进行分析, 以降低由气象数据带来的不确定性; 然后, 通过将 DNDC 模型的氮沉降数据设置为 0 , 再次利用三套气象数据驱动 DNDC 模型, 得到无大气氮沉降情景下中亚 草地 NPP 的动态; 最后, 通过分析两种情景差值, 得到当前大气氮沉降对研究区草地 NPP 的影响。

\subsection{DNDC 模型精度验证}

本文利用在天山北坡不同海拔高度设置的围栏和观测点, 得到的草地地上生物量数据, 验证 DNDC 模型 在中亚地区的适用性。中国新疆天山北坡段发育了四种草地类型,包括平原荒漠草原 (PDG), 海拔低于 650 $\mathrm{m}$; 低山干草原 (LMDG), 海拔在 650-1650 m 之间; 中山森林草地 (MMFM), 海拔在 1650-2700 m 之间和高 山草甸 (AM), 海拔在 2700-3500 $\mathrm{m}$ 之间。我们选择均方根误差法 (RMSE), 分别利用这四种草地类型对 DNDC 模型进行精度验证。 $\mathrm{RMSE}_{n}$ 是模拟值和观测值差的平方和与观测次数比值的平方根, 验证公式为:

$$
\operatorname{RMSE}_{n}=\frac{1}{\overline{O_{n}}} \sqrt{\frac{\sum_{i=1}^{n}\left(S_{i}-O_{i}\right)^{2}}{n}} \times 100 \%
$$

式中, $O_{i}$ 为观测值, $S_{i}$ 为模拟值, $\overline{O_{n}}$ 为观测值的平均, $n$ 为样本容量。 $\mathrm{RMSE}_{n}$ 的值越小, 模型对研究区的适应性 越好, 模拟精度越高, 结果越可靠。一般认为 $\mathrm{RMSE}_{n}$ 值 小于 $20 \%$, 模拟结果较好, 大于 $30 \%$ 时, 模拟效果 较差 ${ }^{[22]}$ 。

\section{2 结果与分析}

\section{1 模型精度验证结果}

本文利用 2007 年和 2008 年在新疆天山北坡的实 测地上净初级生产力 (ANPP) 与模拟得到的 ANPP 进 行模型验证, 结果如图 2 所示。模型模拟得到 PDG、 LMDG、MMFM 和 AM 四种草地类型的 ANPP 与实测数

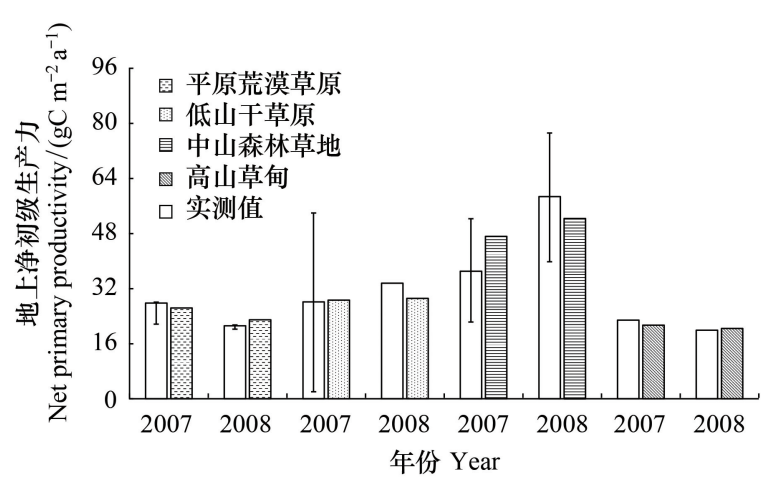

图 $22007 、 2008$ 年 ANPP 模拟值与实测值对比

Fig. 2 Comparison between simulated and measured ANPP in 2007 and 2008 据表现出较好的一致性, $\mathrm{RMSE}_{n}$ 值分别为 $7.36 \% 、 10.24 \% 、 17.38 \%$ 和 $4.37 \%$ 。模型精度能够满足研究需求。

\section{2 三套气候再分析数据比较}

1979-2014 年期间, 中亚气候时空变化显著, 气温表现为显著的增加趋势 $\left((0.03 \pm 0.01)^{\circ} \mathrm{C} / \mathrm{a}, R^{2}=\right.$ $0.40)$, 降水则以 $(2.26 \pm 1.78) \mathrm{mm} / \mathrm{a}\left(R^{2}=0.35\right)$ 的趋势下降(图 3$)$ 。对三组气候数据集的比较表明, CFSR 数

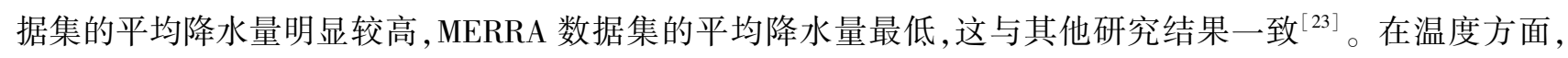
MERRA 数据在所有数据集中值最高。在每个数据集中, 气温的年际变化一致,而在降水方面并不一致。 CFSR 数据集的年平均降水量比 ERA-Interim 数据集高 $36.35 \%$, 比 MERRA 数据集高 $68.34 \%$ 。三个气温数据 集和中亚数据集 (图 4) 的纬向平均温度是相似的,降水数据集也是如此 (图 5), 而在山区因为受地形和海拔 影响较大, 比其他同纬度地区降水偏高, 温度偏低。 


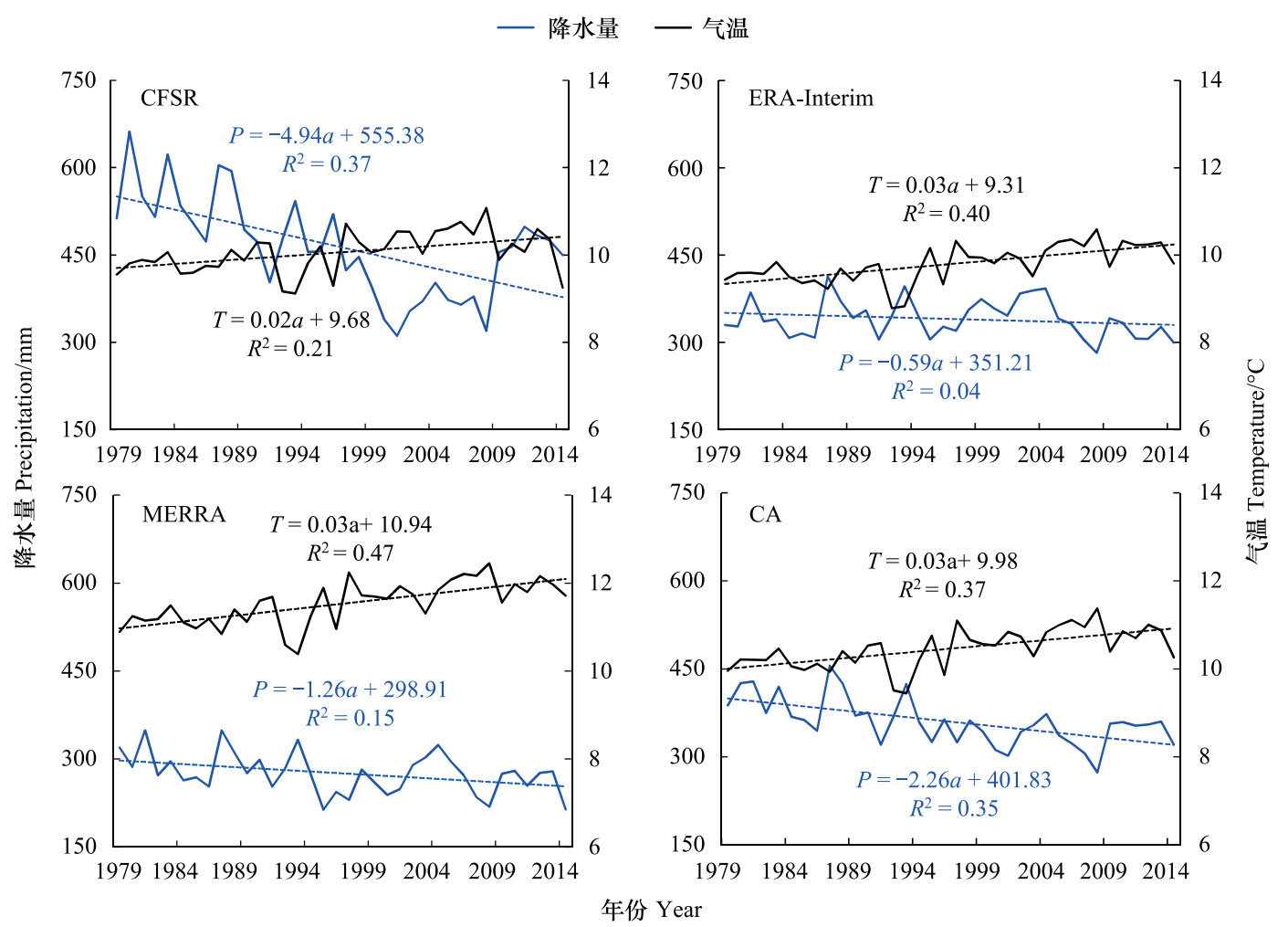

图 3 1979-2014 年中亚年降水量、年平均气温的变化

Fig.3 Variation of annual precipitation and annual average temperature in Central Asia from 1979 to 2014

CFSR: 美国国家环境预报中心的再分析数据集 Climate forecast system reanalysis; ERA-interim: 欧洲中期天气预报中心 ( European Centre for Medium-Range Weather Forecasts, ECMWF) 提供的再分析数据 ECMWF re-analysis; MERRA:美国国家航空航天局提供的再分析数据产品 The modern era retrospective-analysis for research and applications; CA:三套再分析数据的平均值 Central Asia

\subsection{9-2014 年中亚地区草地 NPP 时空分异}

利用 CFSR、ERA-Interim 和 MERRA 三套气象数据驱动 DNDC 模型, 在当前氮沉降水平下对研究区草地 NPP 进行模拟,分别得到了 1979-2014 年不同气象数据驱动的草地 NPP(图 6-7)。由模拟结果可以看出, 三套气象数据模拟得到的平均草地 NPP 为 $(173.16 \pm 31.80) \mathrm{g} \mathrm{C} \mathrm{m}^{-2} \mathrm{a}^{-1}$ 。三套数据结果具有一定的差异, 总体 表现为 CFSR $>$ ERA-Interim $>$ 均值 $>$ MERRA。CFSR 模拟的平均 NPP 为 $(217.04 \pm 31.88) \mathrm{g} \mathrm{C} \mathrm{m}^{-2} \mathrm{a}^{-1}$, ERAInterim 为 $(185.62 \pm 51.46) \mathrm{g} \mathrm{C} \mathrm{m}^{-2} \mathrm{a}^{-1}$,最低值为 MERRA 模拟的 $(116.83 \pm 25.31) \mathrm{g} \mathrm{C} \mathrm{m}^{-2} \mathrm{a}^{-1}$ 。

三套模拟结果在空间分布规律和年际变化规律上, 表现出较强的一致性。在空间分布上,哈萨克斯坦北 部以及阿赖山脉、天山山脉和阿尔泰山脉沿线, 草地 NPP 普遍较高, 大部分区域都高于 $300 \mathrm{~g} \mathrm{C} \mathrm{m}^{-2} \mathrm{a}^{-1}$, 而在 塔吉克斯坦东部地区、乌兹别克斯坦中部和西部地区、哈萨克斯坦中部和西南地区, 以及土库曼斯坦几乎所有 的地区, 草地 NPP 普遍低于 $150 \mathrm{~g} \mathrm{C} \mathrm{m}^{-2} \mathrm{a}^{-1}$ 。这是因为受阿赖山脉、天山山脉和阿尔泰山脉形成的高空屏障 影响, 来自大西洋和北冰洋的水汽被拦截, 导致山脉沿线拥有丰沛的降水, 而中亚内部的乌兹别克斯坦和土库 曼斯坦没有得到足够的水汽补给, 并且该区域夏季平均气温普遍超过 $24^{\circ} \mathrm{C}$, 其蒸发量显著高于降水量 ${ }^{[11]}$, 因 此导致中亚地区草地 NPP 出现了明显的空间分布差异。对照中亚地区草地类型的划分 (图 1 ) 发现, 中亚地 区草地 NPP 与草地类型的划分表现出较强的相关性, 各种草地类型的 NPP 大小总体上表现为森林草甸>温 带草原>荒漠草原。在年际变化上, CFSR, ERA-Interim 和 MERRA 的模拟结果均呈现增加的趋势, 平均为 $(2.67 \pm 1.30) \mathrm{g} \mathrm{C} \mathrm{m}^{-2} \mathrm{a}^{-1}$ 。其中 ERA-Interim 的增速最快, 为 $4.41 \mathrm{~g} \mathrm{C} \mathrm{m}^{-2} \mathrm{a}^{-1}$, MERRA 和 CFSR 增速分别为 1.80 $\mathrm{g} \mathrm{C} \mathrm{m}^{-2} \mathrm{a}^{-1}$ 和 $1.80 \mathrm{~g} \mathrm{C} \mathrm{m}^{-2} \mathrm{a}^{-1}$ 。 

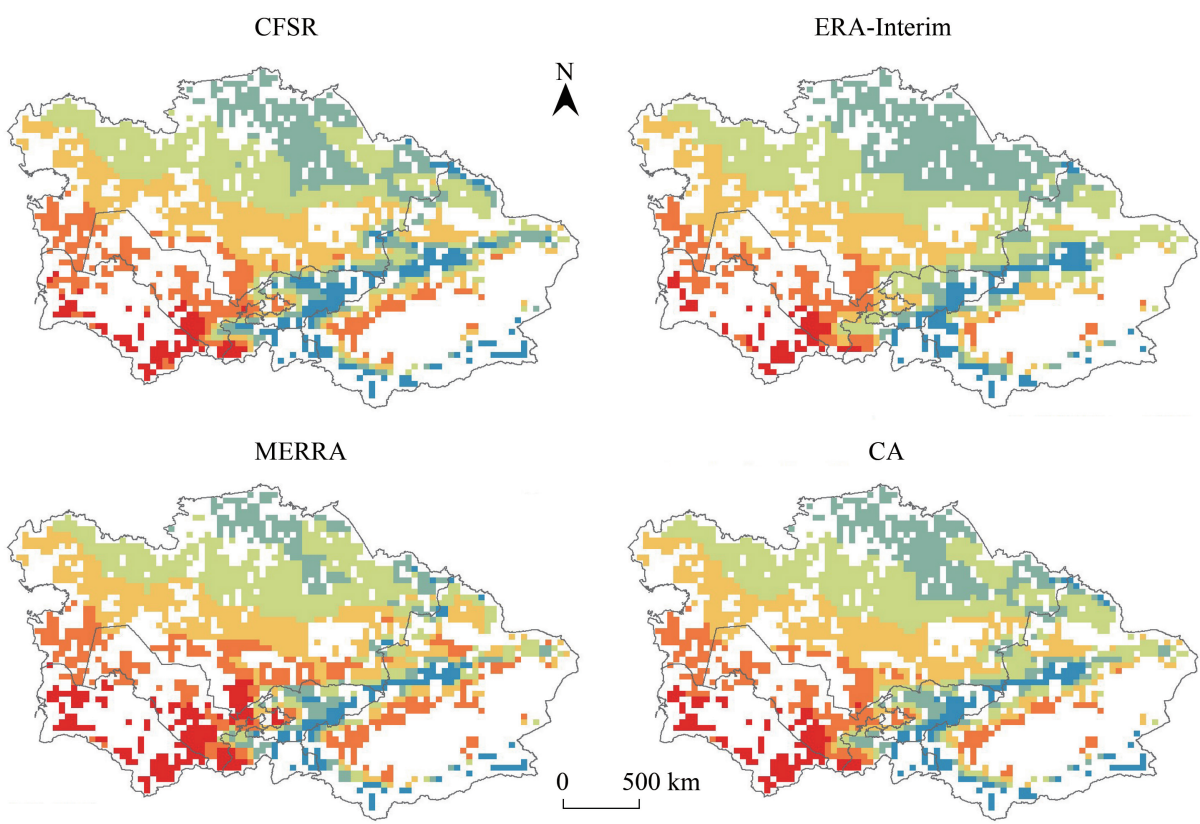

气温 $/{ }^{\circ} \mathrm{C}$

$\begin{array}{lllll}-12 & 0 & 4 & 8 & 12>16\end{array}$

图 4 1979-2014 年中亚平均气温空间格局比较

Fig.4 Spatial patterns of annual average temperature in Central Asia from 1979 to 2014

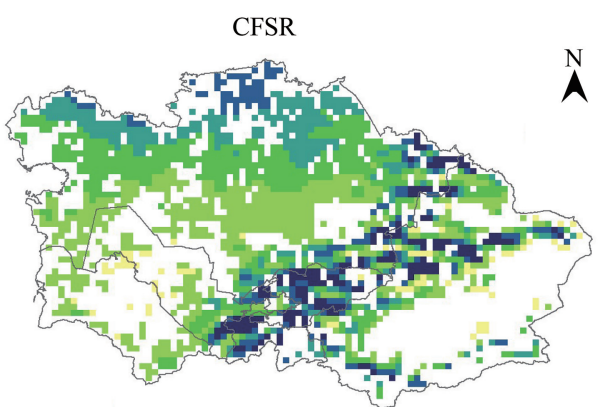

MERRA

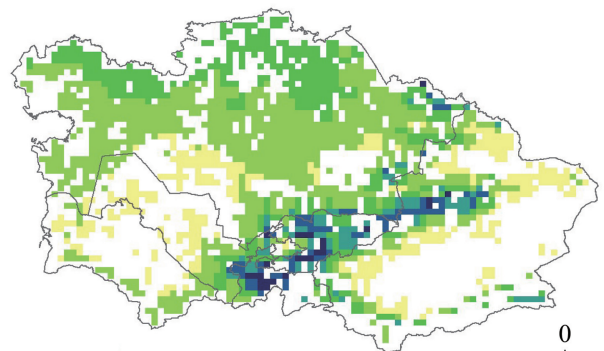

降水 $/ \mathrm{mm}$

$$
0 \quad 150300 \quad 450600>900
$$

图 51979 -2014 年中亚降水空间格局比较

2.4 大气氮沉降对草地 NPP 的影响分析

三套再分析数据模拟得到的草地 NPP 数据显示,氮沉降促进了中亚地区草地 NPP 的增加 (图 8)。 


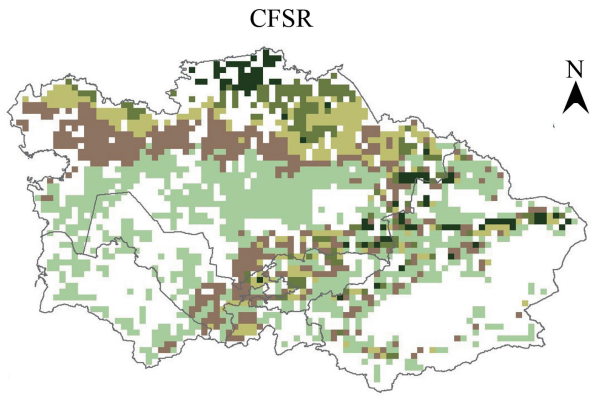

MERRA

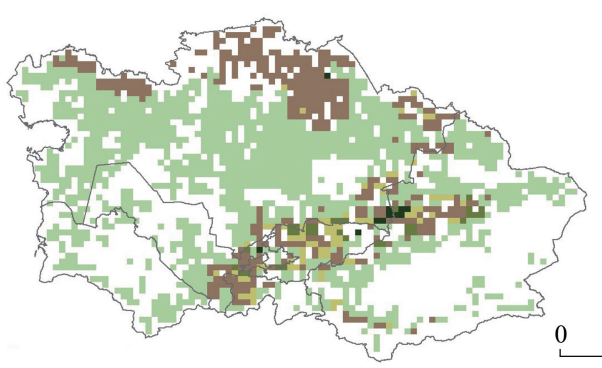

$\mathrm{NPP} /\left(\mathrm{gC} \mathrm{m}^{-2} \mathrm{a}^{-1}\right) \underset{0}{\square} \quad 150 \quad 300 \quad 450>600$

图 $61979-2014$ 年研究区草地平均 NPP 空间格局
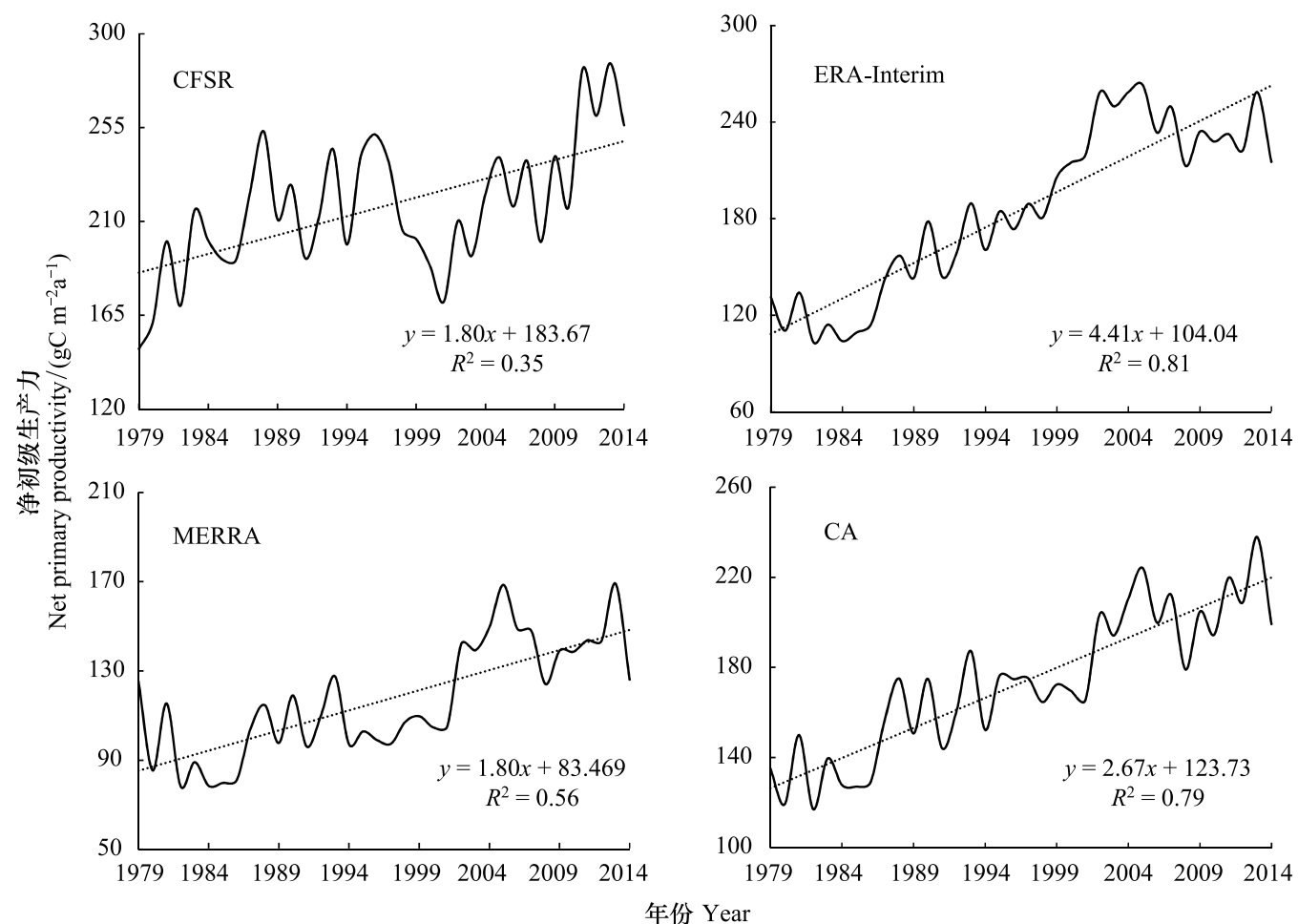

图 7 1979-2014 年研究区平均草地 NPP 年际变化

Fig.7 Interannual variation of averaged grassland NPP in Central Asia from 1979 to 2014 
1979-2014 年,氮沉降使得中亚草地 NPP 增加了 0.42 Pg C。基于 CFSR、ERA-Interim 和 MERRA 数据模拟的 草地 NPP 分别增加了(4.52 \pm 0.97$) \mathrm{g} \mathrm{C} \mathrm{m}^{-2} \mathrm{a}^{-1} 、(3.54 \pm 0.73) \mathrm{g} \mathrm{C} \mathrm{m}^{-2} \mathrm{a}^{-1}$ 和 $(3.63 \pm 0.80) \mathrm{g} \mathrm{C} \mathrm{m}^{-2} \mathrm{a}^{-1}$ 。在空间分 布上,三套再分析数据的模拟结果基本一致,除在吉尔吉斯斯坦部分区域和中国新疆的边界附近的部分区域 表现为负效应或者无影响外, 其他大部分地区, 当前大气氮沉降对草地 NPP 具有促进作用。氮沉降对草地 NPP 产生抑制作用的区域主要分布在哈萨克斯坦北部, 这导致该区域的草地 NPP 平均降低了 $(0.63 \pm 0.14) \mathrm{g}$ $\mathrm{C} \mathrm{m}^{-2} \mathrm{a}^{-1}$ 。除此之外的大部分地区, 当前大气氮沉降对草地 NPP 具有促进作用,氮沉降的促进作用使得该区 域草地 NPP 增加了 $(6.51 \pm 1.27) \mathrm{g} \mathrm{C} \mathrm{m}^{-2} \mathrm{a}^{-1}$ 。在年际变化上(图 9), 草地 NPP 增量波动较大, 但是其变化规律 与降水量的变化规律比较吻合, 草地 NPP 增量随着降水量的增减而增减,并且随着降水量的变化十分显著。

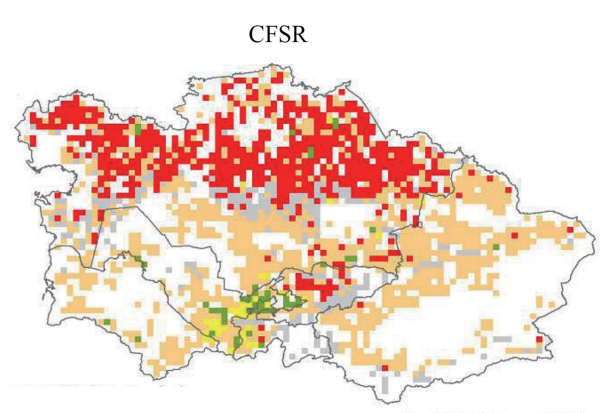

MERRA

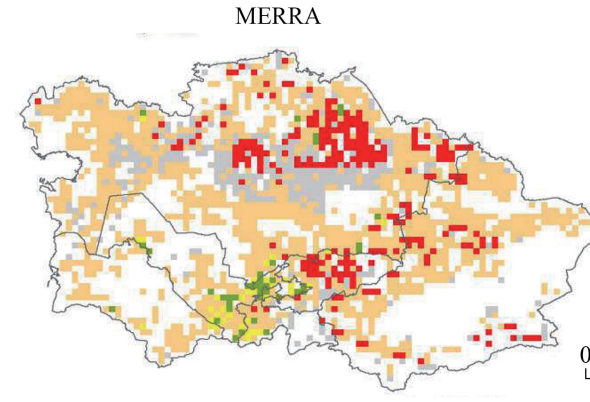

$\mathrm{NPP}$ 变化值 $/\left(\mathrm{gC} \mathrm{m}^{-2} \mathrm{a}^{-1}\right)$

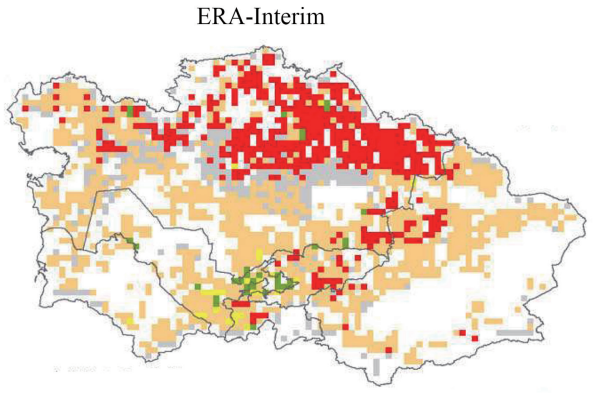

$\mathrm{CA}$

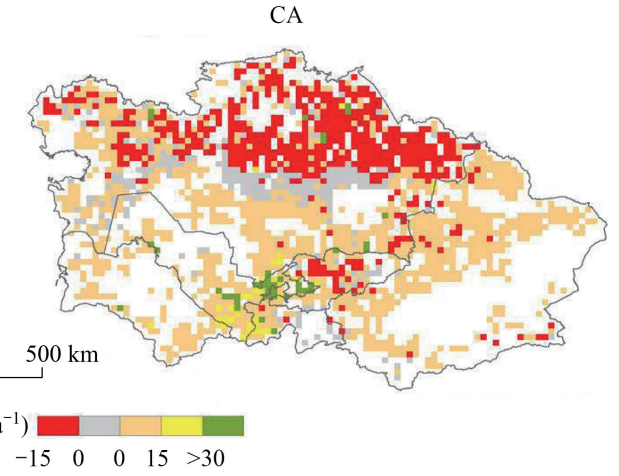

图 8 大气氮沉降对草地 NPP 影响效应空间格局

Fig.8 Spatial pattern of atmospheric nitrogen deposition effects on grassland NPP

\section{3 讨论}

\section{1 模型的不确定性}

DNDC 是生态系统过程模型,其在模拟过程中假设植被组成不变,但是这种假设过于理想化,与复杂多变 的现实情形不符, 导致模拟结果存在偏差。运行 DNDC 模型需要输人大量的参数,模型中植被生态生理模块 的参数种类较多, 但部分参数由于缺乏精确的研究数据在设置时只能依靠模型自带的默认参数值, 这些参数 值可能与研究区实际情况不符, 由此将对模拟精度产生巨大影响。另外,本文只利用了在中国新疆天山北坡 的实测数据对 DNDC 的模拟结果进行验证, 但是中亚地区面积广衰, 气候和地理环境空间差异显著, 导致模型 稳健性较低。

\section{2 中亚草地 NPP 时空分异}

本研究基于三套再分析数据,定量化分析 1979-2014 年中亚地区草地净初级生产力的时空分异。模拟结果 总体表现为 CFSR $>$ ERA-Interim $>$ 均值 $>$ MERRA, 这可能是由于不同气象数据在降水精度上的差异造成的,CFSR、 ERA-Interim 和 MERRA 三套气象数据在海拔为 500-1000 m 的地区,降水精度较高, 但是当海拔超过 $1000 \mathrm{~m}$ 时, CFSR 和 ERA-Interim 两套气象数据的降水被高估, 而 MERRA 在海拔低于 $500 \mathrm{~m}$ 的地区出现了低估 ${ }^{[24]}$ 。 


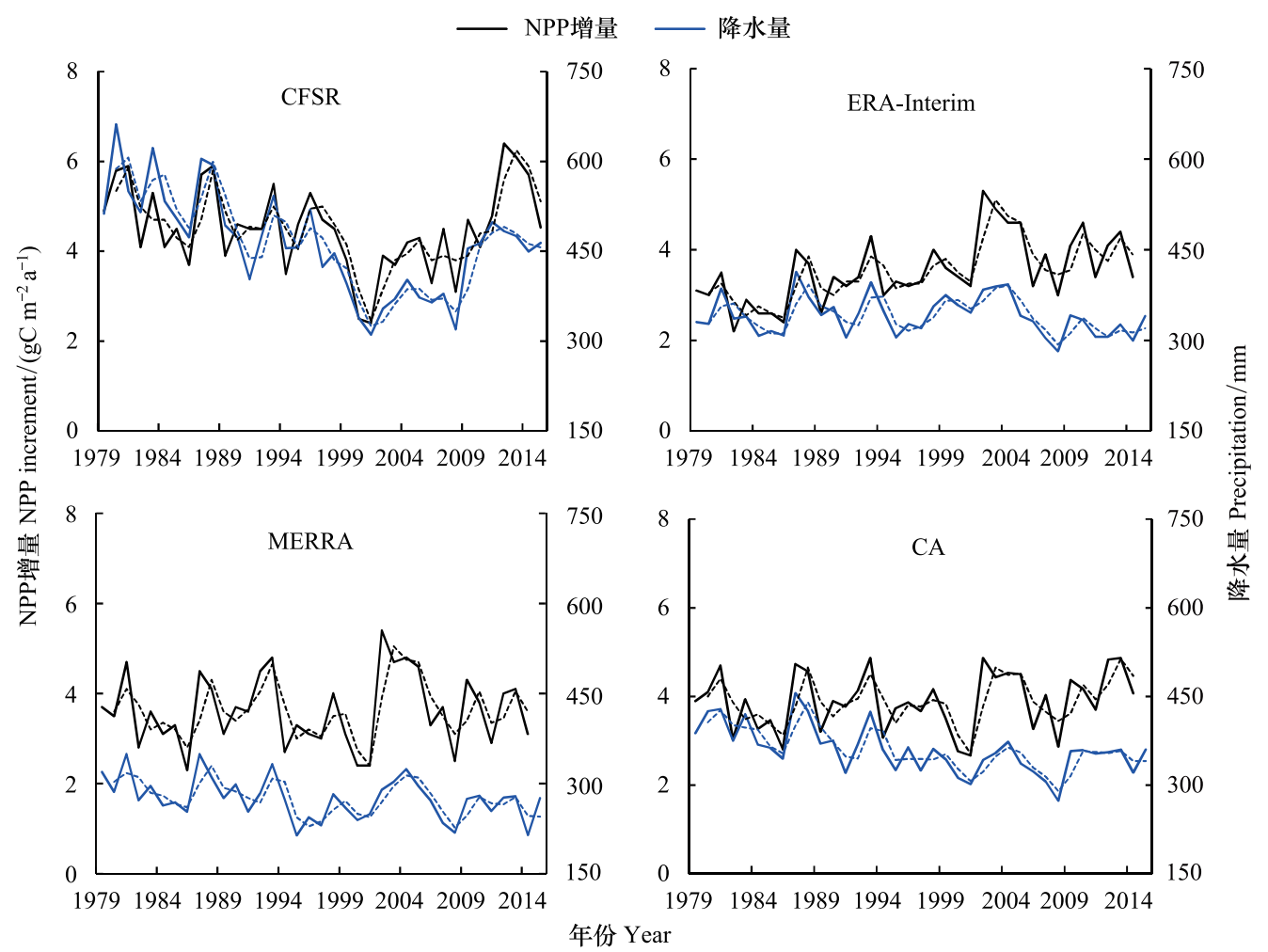

图 9 草地 NPP 增量与降水变化趋势

Fig.9 Relationship between grassland NPP increment and precipitation

近年来,不同学者在草地 NPP 时空分异及其对气候变化的响应方面开展了大量研究。本文估算的年均 草地 NPP 为 $(173.16 \pm 31.80) \mathrm{g} \mathrm{C} \mathrm{m}^{-2} \mathrm{a}^{-1}$, 与朱玉果等 ${ }^{[25]}$ 、朴世龙等 ${ }^{[26]}$ 的研究结果相近。近 36 年中亚草地 NPP 呈 $2.67 \mathrm{~g} \mathrm{C} \mathrm{m}^{-2} \mathrm{a}^{-1}$ 的速率增长, 这也与朱玉果 ${ }^{[25]}$ 等对宁夏的研究结果相近。韩其飞等 ${ }^{[27]}$ 利用 BiomeBGC 放牧模型估算了中亚地区草地生态系统 NPP 年平均值为 $135.6 \mathrm{~g} \mathrm{C} \mathrm{m}^{-2} \mathrm{a}^{-1}$, 且随着时间的推移呈现出波 动下降的趋势, 下降速率为 $0.34 \mathrm{~g} \mathrm{C} \mathrm{m}^{-2} \mathrm{a}^{-1}$, 这与我们得到结果不同, 根本原因在于前者考虑到了中亚日趋 严重的放牧效应, 而没有考虑氮沉降对于草地的施肥效应。任璇等 ${ }^{[28]}$ 的研究指出, 不同的草地类型的 NPP 存在较大差异, 总体来说草甸的 NPP 高于高山亚高山草甸, 其次是平原草地和高山亚高山草地, 而荒漠草地 的 NPP 最低,与本研究中中亚草地 NPP 分布规律基本一致。

\section{3 大气氮沉降对草地 NPP 的影响分析}

本研究结果显示, 氮沉降会对草地生态系统生产力产生显著的影响, 相较于没有氮沉降的情景, 氮添加显 著提高了生产力 $(0.42 \mathrm{Pg} \mathrm{C})$ 。三套气象数据模拟得到的结果大致相同,但在哈萨克斯坦地区存在差异。利 用 MERRA 模拟得到的结果显示当前大气氮沉降对哈萨克斯坦北部和中部的大部分区域草地 NPP 表现为正 效应或者无影响,而 ERA 和 MERRA 的结果则表现为负效应或者无影响; 在哈萨克斯坦西北地区, CFSR 表现 为负效应,而 ERA-Interim 和 MERRA 表现为正效应。氮沉降对草地 NPP 产生抑制作用的地区主要分布在哈 萨克斯坦北部,这导致该区域的草地 NPP 平均降低了 $0.63 \mathrm{~g} \mathrm{C} \mathrm{m}^{-2} \mathrm{a}^{-1}$ 。但是,该区域的大气氮沉降平均值只 有 $0.0556 \mathrm{~g} / \mathrm{m}^{2}$, 相较于世界大部分区域的氮临界负荷 $1 \mathrm{~g} / \mathrm{m}^{2[29]}$ 差别较大, 并且与研究区草地 NPP 增加区域 的平均氮沉降 $0.475 \mathrm{~g} / \mathrm{m}^{2}$ 也有较大差距。因此, 基于已有的研究, 我们无法确定这部分区域草地 NPP 降低是 否是由于达到氮临界负荷而造成的,还需要进行更深人的研究。

在年际变化上,草地 NPP 增量的变化规律与降水量的变化规律比较吻合。因此,氮沉降对草地 NPP 的 影响效应受降水的影响较大。方霞 ${ }^{\left[{ }^{[0]}\right.}$ 在研究中指出, 干旱半干旱区大部分地区的净初级生产力主要受降水 
控制, 降水是制约荒漠生态过程及影响生态系统稳定性的关键要素, 朱士华等 ${ }^{[31]}$ 认为降水是中亚地区草地 NPP 的主要控制因子,因此氮沉降对中亚地区草地 NPP 的影响并不是线性的,它会受到其他环境和气候因子 的影响。

\section{4 结论}

本研究采用 DNDC 模型估算了大气氮沉降对于中亚地区草地 NPP 的影响, 主要得出以下结论: (1) 1979-2014 年间,中亚地区平均草地 NPP 约为 $(173.16 \pm 31.80) \mathrm{g} \mathrm{C} \mathrm{m}^{-2} \mathrm{a}^{-1}$, 但是草地 NPP 时空差异较大,森 林草甸 NPP 最高, 其次是温带草原和荒漠草原。在年际变化上, 中亚地区草地 NPP 有逐年增长的趋势, 草地 $\mathrm{NPP}$ 在以 $(2.67 \pm 1.30) \mathrm{g} \mathrm{C} \mathrm{m}^{-2} \mathrm{a}^{-1}$ 的速度增加。(2)1979-2014 年,大气氮沉降使得中亚草地 NPP 增加了 0.42 $\mathrm{Pg} \mathrm{C}$ 。

\section{参考文献 (References) :}

[ 1 ] 管晓丹,马洁茹,黄建平,黄瑞新,张镭,马柱国. 海洋对干早半干旱区气候变化的影响. 中国科学: 地球科学, 2019,49(6):895-912.

[ 2 ] Rotenberg E, Yakir D. Contribution of semi-arid forests to the climate system. Science, 2010,327 (5964):451-454.

[ 3 ] 刘春静. 中亚干旱区植被退化及典型流域生态环境遥感监测 [D]. 泰安: 山东农业大学,2016.

[ 4 ] 葛怡情,间玉龙,梁艳,干珠扎布,胡国铮,杨劼,高清竹,何世丞,旦久罗布. 模拟降水氮沉降对藏北高寒草甸土壤呼吸的影响. 中国农业 气象, 2019,40(4):214-221.

[ 5 ] Houghton R A. Terrestrial sources and sinks of carbon inferred from terrestrial data. Tellus B: Chemical and Physical Meteorology, 1996,48(4): $420-432$.

[ 6 ] Melillo J M, McGuire A D, Kicklighter D W, Moore B, Vorosmarty C J, Schloss A L. Global climate change and terrestrial net primary production. Nature, 1993,363(6426):234-240.

[ 7 ] 齐玉春,彭琴,董云社,肖胜生,贾军强,郭树芳,贺云龙,间钟清,王丽芹. 不同退化程度羊草草原碳收支对模拟氮沉降变化的响应. 环境 科学, $2015,36(2): 625-635$.

［8］吕超群,田汉勤,黄耀. 陆地生态系统氮沉降增加的生态效应. 植物生态学报, 2007,31(2): 205-218.

[ 9 ] 周峻宇. 中国气态活性氮气候效应及氮沉降临界负荷研究 [D]. 北京:中国农业大学, 2017.

[10] Kipling R P, Virkajärvi P, Breitsameter L, Curnel Y, De Swaef T, Gustavsson A M, Hennart S, Höglind M, Järvenranta K, Minet J, Nendel C, Persson T, Picon-Cochard C, Rolinski S, Sandars D L, Scollan N D, Sebek L, Seddaiu G, Topp C F E, Twardy S, Van Middelkoop J, Wu L H, Bellocchi G. Key challenges and priorities for modelling European grasslands under climate change. Science of the Total Environment, 2016,566-567:851-864.

[11］阿依努尔·玉山江. 中亚五国及中国新疆生态系统健康动态评价研究 $[\mathrm{D}]$. 乌鲁木齐:新疆大学,2019.

［12］陶治,张元明. 中亚干旱荒漠区植被碳储量估算. 干旱区地理, 2013,36(4) :615-622.

[13] Han Q F, Li C F ,Zhao C Y,Zhang Y Q, Li S B. Grazing decreased water use efficiency in Central Asia from 1979 to 2011. Ecological Modelling, 2018,388:72-79.

[14] Rienecker M M, Suarez M J, Gelaro R, Todling R, Bacmeister J, Liu E, Bosilovich M G, Schubert S D, Takacs L, Kim G K, Bloom S, Chen J, Collins D, Conaty A, Da S A, Gu W, Joiner J, Koster R D, Lucchesi R, Molod A, Owens T, Pawson S, Pegion P, Redder C R, Reichle R, Robertson F R, Ruddick A G, Sienkiewicz M, Woollen J. MERRA: NASA`s Modern-Era Retrospective Analysis for Research and Applications. Journal of Climate, $2011,24(14): 3624-3648$.

[15] Dee D P, Uppala S M, Simmons A J, Berrisford P, Poli P, Kobayashi S, Andrae U, Balmaseda M A, Balsamo G, Bauer P, Bechtold P, Beljaars A C M, van de Berg L, Bidlot J, Bormann N, Delsol C, Dragani R, Fuentes M, Geer A J, Haimberger L, Healy S B, Hersbach H, Hólm E V, Isaksen L, Kållberg P, Köhler M, Matricardi M, McNally A P, Monge Sanz B M, Morcrette J J, Park B K, Peubey C, de Rosnay P, Tavolato C, Thépaut J N, Vitart F. The ERA - Interim reanalysis: configuration and performance of the data assimilation system. Quarterly Journal of the Royal Meteorological Society, 2011,137(656):553-597.

[16] Saha S, Moorthi S, Pan H, Wu X, Wang J, Nadiga S, Tripp P, Kistler R, Woollen J, Behringer D, Liu H, Stokes D, Grumbine R, Gayno G, Wang J, Hou Y, Chuang H, Juang H H, Sela J, Iredell M, Treadon R, Kleist D, Van Delst P, Keyser D, Derber J, Ek M, Meng J, Wei H, Yang R, Lord S, van den Dool H, Kumar A, Wang W, Long C, Chelliah M, Xue Y, Huang B, Schemm J, Ebisuzaki W, Lin R, Xie P, Chen M, Zhou S, Higgins W, Zou C, Liu Q, Chen Y, Han Y, Cucurull L, Reynolds R W, Rutledge G, Goldberg M. The NCEP Climate Forecast System Reanalysis, Bulletin of the American Meteorological Society. 2010,91(8):1015-1058.

[17] Li M,Zhang Q, Kurokawa J I, Woo J H, He K B , Lu Z F, Ohara T, Song Y, Streets D G, Carmichael G R, Cheng Y F, Hong C P, Huo H, Jiang X J, 
Kang S C, Liu F, Su H, Zheng B. MIX: a mosaic Asian anthropogenic emission inventory under the international collaboration framework of the MICS-Asia and HTAP. Atmospheric Chemistry and Physics, 2017,17(2):935-963.

[18] Li C S, Frolking S, Frolking T A. A model of nitrous oxide evolution from soil driven by rainfall events: 1 . Model structure and sensitivity. Journal of Geophysical Research: Atmospheres, 1992,97 ( D9) :9759-9776.

[19］刘思源. 基于 DNDC 模型的稻田作物施肥生命周期评价与施肥方案模拟优化研究 [D]. 杭州: 浙江大学,2019.

[20］李长生. 土壤碳储量减少: 中国农业之隐患——中美农业生态系统碳循环对比研究. 第四纪研究,2000,20(4):345-350.

[21] 刘宁,韩娟,刘璐璐, 张否,刘杨, 温晓霞. 应用 DNDC 模型模拟沟垄集雨种植对陕西省玉米产量的影响. 西北农业学报,2016,25 ( 5): $691-701$.

[22] 周文强, 孙丽,蔵淑英, 刘晨, 张玉兰,薄欣, 阎炳和, 张远. 气候变化对松嫩平原西部土壤有机碳及作物产量的影响研究. 环境与发展, $2017,29(2): 31-36$.

[23] 范涁涁. CFSR、ERA-Interim 和 MERRA 三套再分析数据表征新疆温度和降水的适用性分析 [D]. 北京: 中国科学院大学, 2013.

[24] 胡增运,倪勇勇,邵华,殷刚,艳燕,贾超君. CFSR、ERA-Interim 和 MERRA 降水资料在中亚地区的适用性. 干旱区地理, 2013, 36 (4) : 700-708.

[25] 朱玉果,杜灵通,谢应忠,刘可,宫菲,丹杨,王乐,郑琪琪. 2000-2015 年宁夏草地净初级生产力时空特征及其气候响应. 生态学报,2019, 39 (2) $: 518-529$.

[26] 朴世龙, 方精云, 贺金生, 肖玉. 中国草地植被生物量及其空间分布格局. 植物生态学报, 2004,28(4):491-498.

[27] 韩其飞,陆研,李超凡. 气候变化对中亚草地生态系统碳循环的影响研究. 干旱区地理,2018,41(6):1351-1357.

[28] 任璇,郑江华,穆晨, 间凯,刘永强,温阿敏,杨会枫. 新疆近 15 年草地 NPP 动态变化与气象因子的相关性研究. 生态科学, 2017,36(3): 43-51.

[29］周晓兵,张元明. 干旱半干旱区氮沉降生态效应研究进展. 生态学报, 2009,29(7):3835-3845.

[30] 方霞. 中国干旱半干旱生态系统生产力和碳动态对气候变化响应的数值模拟研究 [D]. 乌鲁木齐: 新疆大学, 2018.

[31] 朱士华,艳燕,邵华,李超凡. 1980-2014 年中亚地区植被净初级生产力对气候和 CO2 变化的响应. 自然资源学报, 2017,32 (11)： 1844-1856. 